\title{
Fast-Constructed Marine and Port Structures
}

\author{
Doubrovsky Michael $^{1}$, Poizner Mikhail ${ }^{2}$, Oganesyan Virginia ${ }^{3}$ and Oganesyan Anett ${ }^{1}$ \\ 1. Odessa National Maritime University, Odessa 65029, Ukraine \\ 2. State R\&D Institute of Marine Transport, Odessa 65058, Ukraine \\ 3. Ukrainian Sea Ports Authority, Odessa 65026, Ukraine
}

\begin{abstract}
In order to provide short construction period and to avoid bulky technologies in maritime conditions some rational structures and installation methods are worked out. These methods may be applied for erection of temporary (seasonable) near-shore constructions; they are comparatively cheap and do not involve heavy construction equipment and mechanisms.
\end{abstract}

Key words: Temporary berth structure, shore protection, maritime construction.

\section{Introduction}

The most important practical task of marine and harbor engineering is to create rational designs of structures that are capable to react flexibly to possible changes in the conditions and periods of operation of the facilities and to the invention of new materials and technologies. One of the promising ways to resolve this urgent problem is to develop design and technological solutions that ensure maneuverability in designs of marine and port structures [1].

The usual practice frequently tells that berths are operated inefficiently when they are used for handling ships during navigation period only or in between storm periods while they have to withstand extreme non-operational loads - wave, wind, ice, etc.- - throughout the year. It refers, primarily, to passenger terminals in the roads and to other structures that work at the unprotected coasts [2]. Besides, the fixed marine and harbor structures produce, in a number of cases, a negative impact on a natural regime of the coastal zone (formation of alongside coast flow of sediments, etc.). So, an existence of fixed berths in the periods of reduced intensity or suspension of their operation (these periods, as a rule, coincide with most

Corresponding author: Michael Doubrovsky, Ph.D., Dr.Sc., Professor, research fields: port, coastal, marine and geotechnical engineering. rigorous climatic seasons) leads to design of structures having high strength and stability safety factors which increase capital expenditure as well as unjustified operating expenses because the structure may be damaged during storms and other unfavorable periods.

The task can be resolved by means of new design solutions that provide for a transformation of the outline scheme of construction. These solutions should be based on the constructions built of industrial standard modules that can be mounted and dismantled with the use of conventional technological processes [3, 4].

\section{Effective design approach: constructions with transformable structures}

To reduce capital and operating expenses, a construction is designed $[5,6]$ that consists of the foundation blocks 1 , supports 2 and superstructure 3 (Fig. 1a). The lower ends of supports 2 are provided with fixing locks 4 and the foundation blocks 1 incorporate sleeves 5 , slots 6 for the fixing locks 4 and mounting ties 7; when the berth is to be preserved, the openings of sleeves 5 are closed with plugs 8 . Foundation blocks 1 are mounted on stone bedding 9 .

The connection between foundation blocks 1 and supports 2 can be disjointed because locks 4 of supports 2 are freely supported on blocks 1 through slots 6 , same as the lower ends of supports 2 arranged 
inside sleeves 5; the mounting ties 7 can be disassembled as well. Availability of the fixing locks and their arrangement inside the slots 6 of blocks 1 precludes horizontal displacements of frames that are connected with the blocks while the mounting ties 7 preclude vertical lifting of supports 2 by wave loads.

The foundation blocks can be made not only of reinforced concrete units but also of tubular pipe sections driven into soil to foundation surface level, the diameter of such piles being by $5 \%$ more than the support diameter.

The structure is erected as follows:

- the foundation (stone bedding 8) is prepared to place foundation blocks 1 with the aid of $50 \mathrm{kN}$ lifting capacity floating cranes;

- the foundation blocks 1 (of $5 \times 3 \times 1 \mathrm{~m}$ approximate dimensions and of up to $25 \mathrm{t}$ mass) are arranged with the aid of $500 \mathrm{kN}$ lifting capacity floating cranes and the actual distance between longitudinal and transversal axes of sleeves 5 of blocks 1 is measured (sleeve diameter exceeds the pile diameter by $5 \%$ );

- frames made of supports 2 joined by a superstructure 3 are mounted on shore in accordance with the actually measured distances (e.g., by use of dia. 420-920 mm steel pipes). Specifically, the frame may consist of four supports located in the corners of the rectangle;

- the frames are mounted on foundation blocks 1 , the lower ends of supports 2 are inserted into sleeves 5 and fixing locks 4 are arranged in slots 6 of blocks 1 (a $500 \mathrm{kN}$ lifting capacity floating crane may be used for such assembling);

- divers check and align fixing locks 4 relative to slots 6 , and secure mounting ties 7;

- to make superstructure 3 more rigid, the slabs of the neighbouring frames can be joined together with temporary mounting links.

After the structure is no longer to be operated, it is disassembled in the following sequence:

- the temporary mounting links between the slabs of superstructure 3, if any, are removed; the divers disconnect mounting ties 7; the floating cranes lift the frames so that fixing locks 4 come out of slots 6 and the lower ends of supports 2 come out of sleeves 5 of blocks 1;

- the divers close the openings of sleeves 5 by plugs;

- the frames are taken ashore where they can be used as frames for temporary warehouses or other premises until they are used again to their main purpose.

The described solution allows avoiding of extreme non-operational loads on the berth and, consequently, reduction of the design sections of the structure elements and the amount of materials used to manufacture them. Also, it becomes possible to make the operation mode of the structure more rational due to a possibility of temporary preservation of the berth.

In order to reduce the cost of the structure due to reduction of material consumption, simple design and shorter construction period, a marine/port structure (Fig. 1b) has been designed that includes a two-row block of inclined walls 1 connected with rigid ties 2 [1, 2]. Between the walls 1 the block is provided with a mounted tank 3 with a superstructure slab 4 and a stone fill 5 (the bottom of tank 3 does not touch bottom 6).

The structure is erected as follows. The two-row block is mounted on soil foundation 6 either with tank 3 or without it. If the block is driven into the bottom soil after mounting it on the foundation, tank 3 is installed being filled with stone 5 , so the vertical load is transmitted to the inclined walls. Such way of block installation is expedient whenever the bottom soil is homogeneous and the block skewing is excluded. Generally, when the bottom soil may be non-homogeneous, tank 3 is installed at first and then stones 5 are filled in so as to drive the block into the bottom. In doing so, it is possible to take into account uneven settlements of the block and make them uniform.

Application of the block of described design makes 


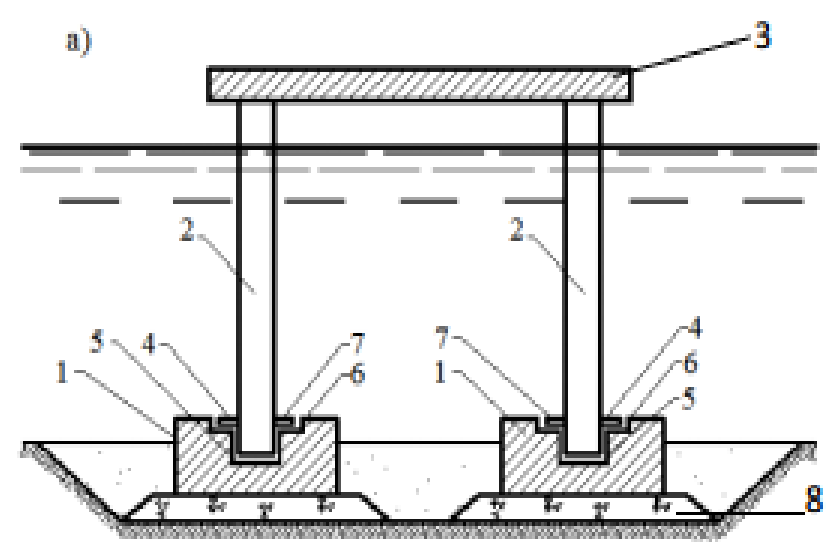

b)

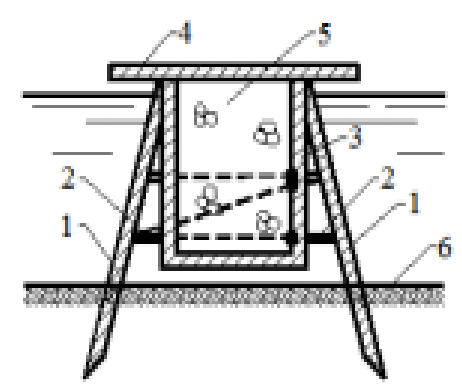

c)

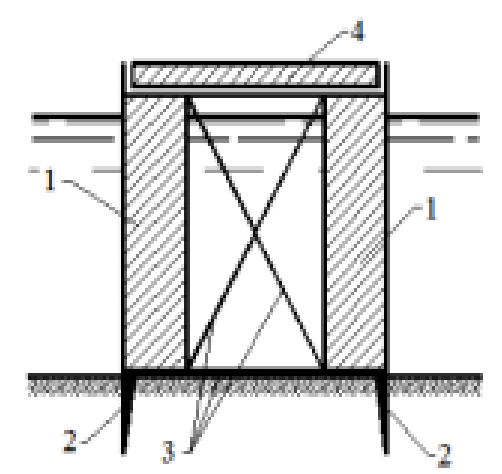

Fig. 1 Constructions with transformable structures: a) use of removable modules; b) units with mounted tank; c) use of pontoon units.

it possible to achieve the following advantages:

- improved stability due to better use of the stone filling (the stone weight is included into restraining force);

- simplified assembling technology (absence of various-type operations, erection by use of enlarged blocks; stone can be filled into the tanks on the shore in advance to avoid maritime operations);
- repeatability of the method's application in different places using the same structural elements (removal of the filled tank, pulling out the two-wall block out of foundation with a floating crane and replacing it to another site).

In order to reduce material consumption and to shorten construction period, a structure is developed [1, 2] that consists of the walls made as vertically arranged 
pontoons 1 whose lower ends are provided with edges 2 ; the walls are joined with rigid ties made as frames 3 , a superstructure 4 is arranged above the walls (Fig. 1c).

The structure can be erected in the following sequence:

- the block of walls/pontoons 1 interconnected with frames is delivered afloat by a tug (the block in transit can be arranged horizontally so as to make a catamaran);

- the block is put into a design position by partial filling pontoons 1 with water while full ballasting is achieved by driving edges 2 of the pontoons into the bottom soil; if the weight of the pontoons filled with water is insufficient to install the edges 2 into their design position, it is possible to put additional loads on pontoons 1;

- the superstructure 4 is mounted; if the aim of the construction is a berth, the block is equipped with fenders and mooring arrangements.

At the stage of the structure operation, the pontoons act as load-bearing walls and stability is ensured with edges 2 driven into the bottom soil.

It is possible to make a berth for handling Ro-Ro ships using a set of blocks as this berth's type does not require cargo-handling cranes, or a pier for mooring ships on both sides of the blocks, or a temporary coast protection structure.

If it is necessary to remove the structure after it fulfilled its functions or to change its application, the structure can be dismantled. After disassembly and removal of the superstructure, the edges may be pulled from the bottom soil (partially of fully) by pumping the ballast water from the pontoons and by use of the buoyancy force. Further dismantling is accomplished with the aid of floating cranes or tugs.

Application of the proposed solution ensures, as compared with known options, achievement of the following technical advantages: reduction of material consumption (no piles are used), acceleration of the construction, simplification of the construction technology and making it possible to quickly disassemble the structure and to erect it at the new site.

\section{Improved installation technology for coast protection structures}

Usually harbor structures are built "in water" with the use of various floating facilities. Such technological approach has a number of deficiencies. For example, in some cases it is required to use special refuge ports for auxiliary ships and floating cranes. Obviously this may deteriorate technical and economic indicators of the future structure. The use of existing commercial ports for such purposes is difficult from a practical viewpoint as such are busy with their basic operational activity.

There exist methods to build port structures "from a shore" or combined methods, but traditional technologies necessitate a wide application of powerful shore cranes during construction. Moreover, a chance that shore cranes can be "put to sea" while mounting the structures will depend on weather conditions.

A rational method to build coast protection structures is suggested, in particular, it relates to dams, groins, spurs and jetties [5-7]. Such structures may be installed by shoving (or launching, i.e. by pushing blocks from ashore to the sea by means of hydraulic jacks). The launching method is most efficient when building coast protection structures at shallow coasts, besides it allows working in bad weather conditions.

The jack battery is made of a design number of jacks that find their support in special holes in the thrust plate. Proper arrangement of jacks in the battery is achieved by a metal shell with tightening locks. Uniform transmission of force from the jack stack may be accomplished by a slab that is mounted on the external side of the jack block and moves together with the jacks' pistons. Elevation of the jack block is chosen taking into account the gravity center of the unit to be pushed (Fig. 2).

Construction is started from carrying in stones by trucks and subsequent filling it into the dam bedding with the aid of bulldozers located on the pontoons (see Fig. 2a). After stone is leveled, special guides made of 
rails or pipes are put onto the bedding and fixed therein. The guides are interconnected with metal straps with downward bent ends. The ends are buried into the stone bedding and secure the position of the guides. The sea ends of the guides are provided with a backstop that restricts the displacement of the head unit when it is moved.

Jack blocks 1 and inventory (reusable) slabs 2 and 3 are mounted by a shore crane located on the shore support (see Fig. 2b).

A required pressure is built up in the jack system cylinders and the reusable slab 3 is displaced forward thereby moving the head unit of the dam for a distance equal to the jack piston travel. After the pressure in the jack cylinders is released, an insert block is installed in the space formed between the head unit of the dam and the plate. Later, the shoving operation is repeated. After the necessary number of installations of the insert unit, they are removed by the crane and the next dam block is mounted instead of them. The movement of the dam block is accomplished in accordance with the above process.

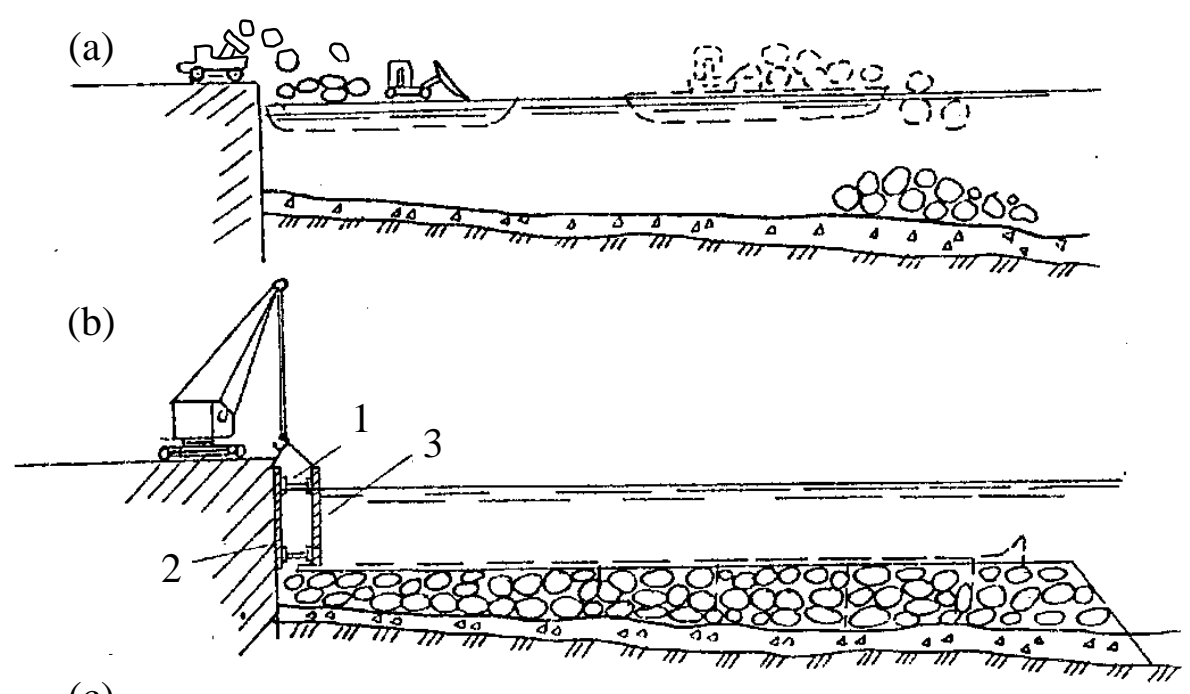

(c)

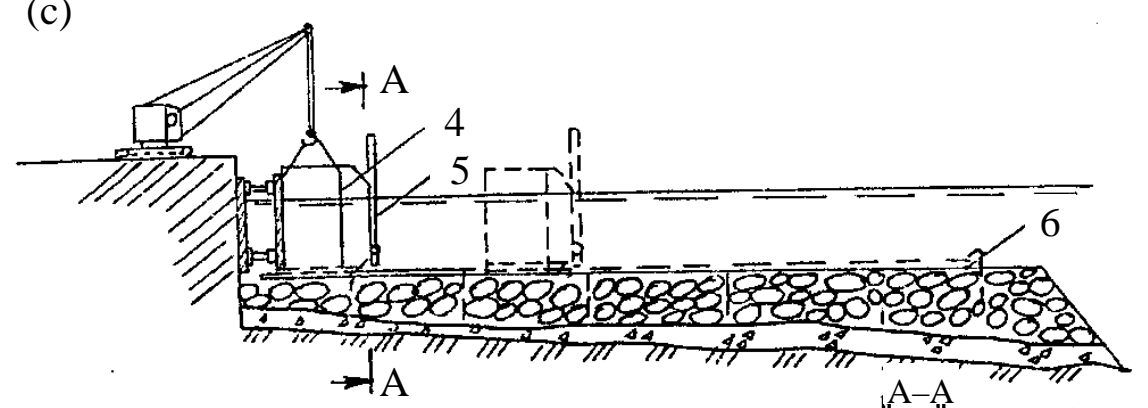

(d)

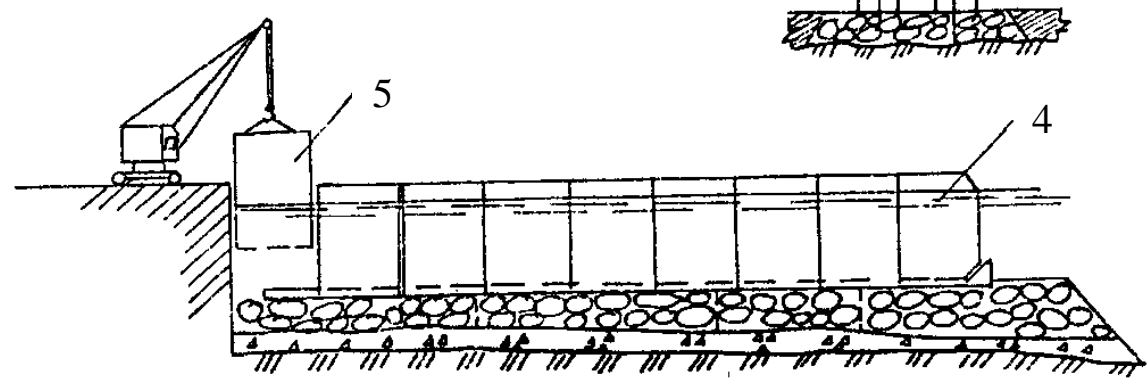

Fig. 2 Construction of the gravity type dam (dyke, groin, spur, jetty) by shoving. 
The head block 4 of the dam is made with a higher front edge and through rectangular slots to receive guides 5 with backstop 6 (see Fig. 2c). Whenever the stone bedding is lengthened section by section, the first section of the guides is laid by a shore crane with the aid of divers and the head unit is pushed forward by a jack up to the end of the laid section. On releasing pressure in the jacks, the backstop slab returns to its initial position and the next unit is placed in the place that becomes vacant. Truck crane moves forward along the ready part of the structure and handles the next section of the guides that is hinged above the unit slots. After the guides are lowered onto stone bedding, the unit is moved forward along the guides leaving them in the dam body.

Extension of next elements (dam units, concrete inserts) and their movements are repeated until the head unit reaches its design position. Afterwards, the jack battery is removed by a shore crane and a rear unit 7 is positioned in place (see Fig. 2d).

When selecting the jacks, the value of the pushing force $E j$ may be determined according to the formula:

$$
E_{j} \geq \frac{m_{c}}{K_{r}} M g f,
$$

where $E j$ - moving force of the jack battery required for moving the dam elements; $m_{C}$ - coefficient of work conditions; $K_{r}$-reliability factor assumed depending on the mass of coast protection structure; $M$-mass of the above water and underwater parts of the dam; $g$-acceleration of gravity; $f$-design coefficient of friction along the sliding surface (concrete units along the stone bedding).

Practical experience indicates that erection of sea dams by launching reduces construction costs by 35\% and shortens the construction period by $25 \%$ [8].

\section{Conclusions}

Proposed construction and technological solutions have their specific niche for practical implementation shallow water coast, the absence of significant lateral loads. In such conditions, these innovations may demonstrate important advantages: cost-effectiveness and reduction of construction terms.

\section{References}

[1] Doubrovsky, M. P., and Poizner, M. B. 1998. New development of port structures design and construction. Proceedings of the Fourth International Conference Littoral' 98 of the European Coastal Association for Science and Technology. Barcelona, Spain: 445-453.

[2] Doubrovsky, M. P., and Poizner, M. B. 2008. Foundations of onshore and offshore constructions on Ukrainian Black Sea and Azov Sea coasts. Proceedings of 11th Baltic Sea Geotechnical Conference "Geotechnics in Maritime Engineering”. Gdansk, Poland. Volume 2: 935-940.

[3] Poizner, M. B., Doubrovsky, M. P. and Gurin A.I. 2000. IABSE Congress Report, Volume 16, \#12, International Association for Bridge and Structural Engineering: 995-1001.

[4] M.P. Doubrovsky, G.I. Meltsov, R. Pereiras Papova, A. Zhussupbekov. 2015. Proceedings of the 16th European Conference on Soil Mechanics and Geotechnical Engineering. Edinburg, UK: 1273-1278.

[5] Doubrovsky, M. P., and Poizner, M. B. 2000. Marine Engineering and Geotechnique. Odessa, DRUK, p. 163.

[6] Doubrovsky, M. P., and Poizner, M. B. 2016. Innovative Development of Coastal, Port and Marine Engineering. Lambert Academic Publishing, Germany, p. 125.

[7] Poizner, M. B., Tsymarna, N. A., Yakovenko, V. G., and Mishin A. V. 1984. Method of Construction of Shore Protection Structures. Inventors Certificate of USSR \# 1094886. Moscow.

[8] Poizner, M. B., Tsymarna, N. A., Yakovenko, V. G., and Mishin A. V. 1984. "Construction of the Marine Groin by Shoving Method.” Transport Construction 6: 23-4. 